\title{
Corrosion Effects on Fracture Toughness Properties of Wire Arc Additively Manufactured Low Carbon Steel Specimens
}

\author{
Anna Ermakova and Ali Mehmanparast *(D)
}

Department of Naval Architecture, Ocean and Marine Engineering, University of Strathclyde, Glasgow G1 1XQ, UK; anna.ermakova@strath.ac.uk

* Correspondence: ali.mehmanparast@strath.ac.uk

check for updates

Citation: Ermakova, A.; Mehmanparast, A. Corrosion Effects on Fracture Toughness Properties of Wire Arc Additively Manufactured Low Carbon Steel Specimens. Metals 2022, 12, 238. https://doi.org/ $10.3390 /$ met 12020238

Academic Editor: Pasquale Cavaliere

Received: 23 December 2021

Accepted: 25 January 2022

Published: 27 January 2022

Publisher's Note: MDPI stays neutral with regard to jurisdictional claims in published maps and institutional affiliations.

Copyright: (c) 2022 by the authors. Licensee MDPI, Basel, Switzerland. This article is an open access article distributed under the terms and conditions of the Creative Commons Attribution (CC BY) license (https:// creativecommons.org/licenses/by/ $4.0 /)$.

\begin{abstract}
The emerging wire + arc additive-manufacturing (WAAM) technique has significant potential to improve material design, as well as manufacturing cost and efficiency of structural components such as offshore wind turbines and subsequently reduce the levelised cost of energy (LCoE). Welded joints in offshore structures are usually considered potential spots for crack initiation due to the combination of high stress concentration at the weld toes, residual stresses introduced by the welding process and cyclic loading conditions in harsh, corrosive marine environments. The WAAM technique is a deposition method consisting of repetitive welding process that can be used as an alternative manufacturing technique for fabrication or repair of structural components. An important issue that needs to be understood in structural-integrity assessment of WAAM-built components is fracture-toughness behaviour. In particular, the sensitivity of fracture-toughness properties to corrosive environments must be examined in order to extend the application of the WAAM technique to offshore wind structures. Therefore, in this study, fracture-toughness tests were conducted on WAAM-built compact-tension specimens made of ER70S-6 and ER100S-1 steel that were initially exposed to a seawater corrosive environment prior to testing. All fracture-toughness tests were performed at room temperature, and crack length was estimated using the compliance method with a clip gauge attached onto the knife edge of the specimens. The obtained results, which include load vs. load-line displacement and $J$-integral vs. crack extension, were analysed and compared with the results of tests in air, without any exposure to seawater. The conclusions of this study show that corrosive environments affect the yield stress and $R$-curves of the selected materials and contribute to the overall understanding of the design requirements for functionally graded structures fabricated by means of WAAM technique for offshore applications.
\end{abstract}

Keywords: WAAM; additive manufacturing; fracture; corrosion; offshore wind turbines

\section{Introduction}

Corrosion is one of the key factors that affects the short- and long-term performance of steel structures exposed to harsh offshore environments, e.g., offshore wind turbines. The residual mechanical properties of rusty steel structures need to be assessed to ensure safety and provide further repair and reinforcement plans for the damaged structure. Fracture is a common and dangerous mode of failure, especially if the behaviour is brittle or quasibrittle, as fractures may occur suddenly without a visible warning. In ductile steels, brittle fractures can happen if concentration forces exist, for instance, at an initiated fatigue crack, weld defect or geometry notch [1]. Moreover, corrosion pits on damaged steel surfaces can act as stress concentrators and benefit the fracture-failure mechanisms [2,3]. Therefore, it is likely that the fracture behaviour of corroded steel parts will degrade over time.

The new wire-arc additive manufacturing (WAAM) technique offers a variety of benefits for various industries. Compared with other additive manufacturing (AM) techniques, such as powder-based methods, WAAM is known for lower manufacturing costs and high deposition rates for large-scale structural fabrication, which leads to reduction 
in manufacturing lead time [4-7]. Nevertheless, this process consists of a pure welding mechanism, depositing one metal layer on top of another while constantly reheating and cooling down the built part. This causes uncertainties in microstructural homogeneity and isotropy of mechanical properties [8,9]. Additionally, inherent weld defects can be considered potential weak spots where fracture and fatigue failure can develop [10]. Thus, in order to minimise safety risks, the degradation mechanisms of corroded WAAM-built steel components need to be carefully investigated in order to assess the suitability of this technique for offshore applications.

Many studies have been previously conducted to examine corrosion effects on mechanical behaviour of conventionally built metallic specimens and welded joints. Such studies include tensile tests performed on corroded specimens, derivation of empirical models and evaluation methods and prediction of residual mechanical properties [11-18]. Moreover, some studies have investigated the residual performance of degraded corroded steel parts [19-21]. However, only a limited number of papers is available on fracture properties of corroded steel parts, with almost no investigations of corrosion damage effects on fracture behaviour of WAAM-built parts.

A research group examined the fracture-toughness performance of corroded U-notched steel plates [22], and the results revealed significantly degraded fracture properties. According to this study, the ultimate load and fracture toughness decreased for the corroded specimens. Additionally, it was established that the increase in corrosion pits was the driving force behind crack propagation. Another comprehensive test programme by Hou et al. [23] was carried out on the effects of corrosion on mechanical properties of metals used for buried steel pipes, wherein a relationship between corrosion and deterioration of mechanical properties was developed. It was also concluded that both tensile strength and fracture toughness of corroded steel are reduced as a result of corrosion.

The intention of the present study is to investigate the effect of corrosion on fracturetoughness properties of WAAM-built specimens made with different grades of steel, including ER70S-6 and ER100S-1. The WAAM manufacturing setup, specimen extraction and testing procedure are described. Prior to fracture-toughness testing, the specimens were soaked in artificial seawater to assess environmental effects on fracture properties. The test results were analysed and compared with the previously tested WAAM-built specimens without any environmental exposure (i.e., in air and in the absence of corrosion damage). The results produced in this study contribute to the overall knowledge of corrosion behaviour and its effects on fracture properties of WAAM steels in order to evaluate the suitability of this technique for fabrication and repair of offshore wind-turbine structures.

\section{Specimen Fabrication and Preparation Process}

In this study, four specimens were extracted from two different WAAM walls: one made with ER70S-6 welding wire [24] and the other made with ER100S-1 [25]. The chemical composition of each wire is presented in Table 1. Both walls were manufactured using the cold metal transfer (CMT) process with the parameters shown in Table 2 and by employing an oscillation deposition method [26], which is often used for fabrication of relatively thick WAAM walls. The manufacturing setup for the WAAM walls is demonstrated in Figure 1, consisting of a CMT power source, a robotic arm with a CMT torch that simultaneously supplies the shielding gas and the welding wire and an exhaust fan that removes excessive heat and fumes from the WAAM wall. Each wall was deposited in the middle of a base plate cut from an EN10025 rolled structural steel, which was firmly attached onto the working table with eight clamps during the fabrication process in order to minimise any bending or distortion of the base plate and the WAAM wall as a result of high manufacturing temperatures. The clamps were removed once the deposition was completed, and the walls were cooled down to ambient temperature. 
Table 1. Chemical composition of the WAAM wires (wt. \%) [24,25].

\begin{tabular}{ccccccccccc}
\hline & $\boldsymbol{C}$ & $\boldsymbol{M n}$ & $\mathrm{Cr}$ & $\mathrm{Si}$ & $\mathrm{Ni}$ & $\mathbf{M o}$ & $\boldsymbol{S}$ & $\boldsymbol{P}$ & $\boldsymbol{C u}$ & $\boldsymbol{V}$ \\
\hline ER70S-6 & 0.09 & $<1.60$ & 0.05 & 0.09 & 0.05 & 0.05 & 0.007 & 0.007 & 0.20 & 0.05 \\
ER100S-1 & 0.08 & 1.70 & 0.20 & 0.60 & 1.50 & 0.50 & - & - & - & - \\
\hline
\end{tabular}

Table 2. CMT-WAAM fabrication parameters.

\begin{tabular}{cc}
\hline Shielding Gas & $\mathbf{A r}+\mathbf{2 0} \% \mathbf{C O}_{\mathbf{2}}$ \\
\hline Gas flow rate & $15 \mathrm{~L} / \mathrm{min}$ \\
Robot travelling speed & $7.33 \mathrm{~mm} / \mathrm{s}$ \\
Wire diameter & $1.2 \mathrm{~mm}$ \\
Wire feed speed & $7.5 \mathrm{~m} / \mathrm{min}$ \\
Dwell time & $120 \mathrm{~s}$ \\
\hline
\end{tabular}

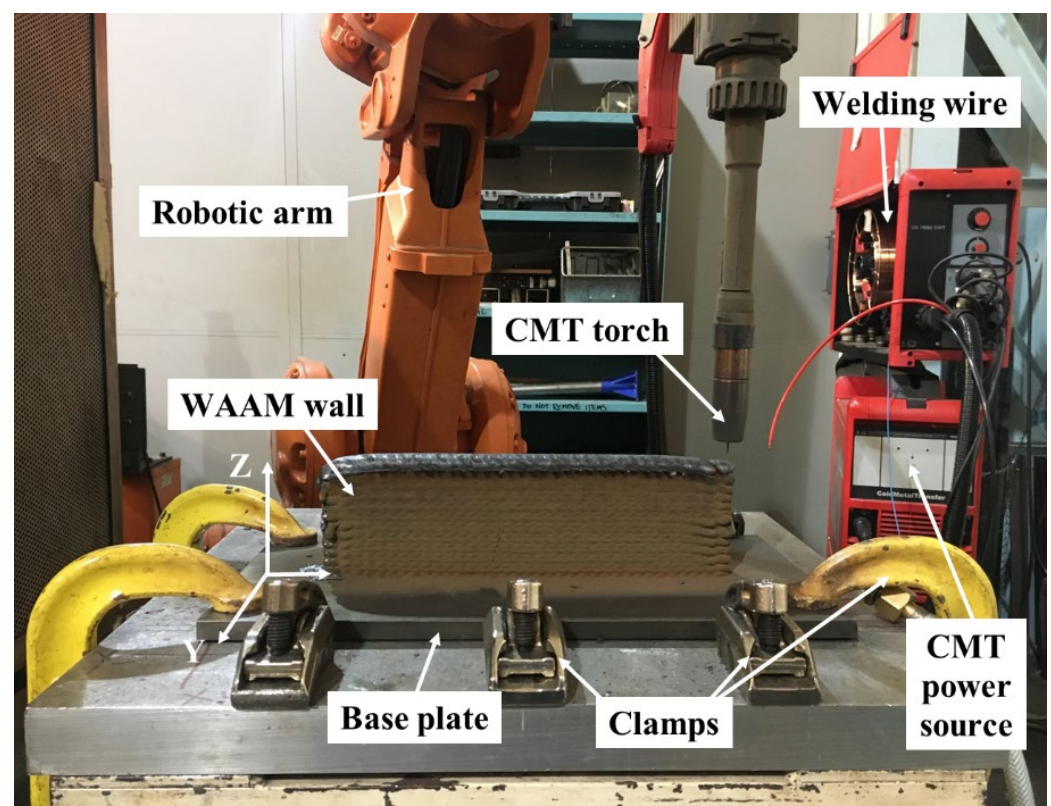

Figure 1. CMT-WAAM setup.

Upon completion of the wall deposition, two notched compact-tension, $C(T)$, specimens from the top $(\mathrm{T})$ half of each wall were extracted using the electrical discharge machining (EDM) method. The specimens from the bottom (B) of the wall were used in a different study. The specimens were extracted in two different orientations with respect to the deposited AM layers: vertical (V), with the crack growth-direction perpendicular to the AM layers; and horizontal $(\mathrm{H})$, with the crack-growth direction along the AM layers, as schematically presented in Figure 2. The specimens were designed in accordance with the ASTM 1820 standard [27] for fracture-toughness testing, with a width of $W=50 \mathrm{~mm}$, a height of $H=60 \mathrm{~mm}$, total thickness of $B=16 \mathrm{~mm}$ and initial crack length of $a_{0}=17 \mathrm{~mm}$ before pre-fatigue cracking. The specimens were not side-grooved (hence $B_{n}=16 \mathrm{~mm}$ ) in order to facilitate the introduction of corrosion damage on the outer surface during exposure to seawater. The fracture toughness, $\mathrm{C}(\mathrm{T})$, specimens made of ER70S-6 and ER100S-1 welding wires were denoted as C-70-1 (T, V), C-70-2 (T, H) and C-100-1 (T, V), C-100-2 (T, H), respectively. Prior to testing, all specimens were fatigue-pre-cracked under cyclic loading conditions using the load-decreasing approach to approximately $32 \mathrm{~mm}(a / W=0.64)$, as advised in the ASTM 1820 standard. The starting fatigue-pre-cracking load was maintained below the maximum allowable load specified in the standard. During the pre-cracking process, an infinitely sharp crack tip is introduced ahead of the machined notch without developing a significant plastic zone ahead of the crack tip. Once the specimens were 
prepared for fracture-toughness testing, they were immersed for 11 days in artificial seawater that was made according to the ASTM D1141-98 standard [28] using deionised water, with the composition shown in Table 3. The temperature of the artificial seawater was maintained between 8.0 and $10.0^{\circ} \mathrm{C}$ using a chiller with a $\mathrm{pH}$ of 8.0 to replicate operational conditions in the North Sea [28].

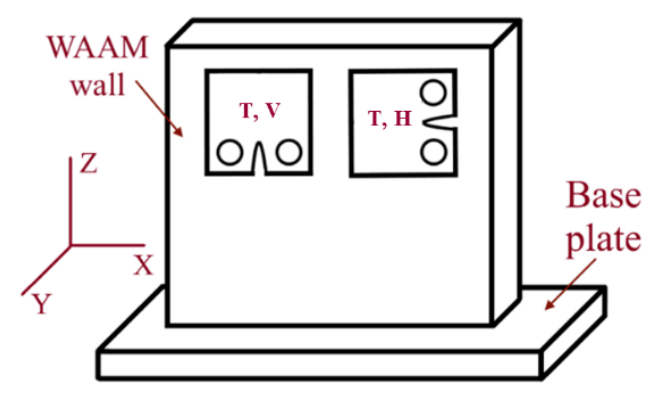

Figure 2. Schematic of the specimen extraction plan from the WAAM wall.

Table 3. Chemical composition of artificial seawater.

\begin{tabular}{cc}
\hline Chemical Compound & Concentration $(\mathrm{g} / \mathrm{L})$ \\
\hline $\mathrm{NaCl}$ & 24.53 \\
$\mathrm{MgCl}_{2}$ & 5.20 \\
$\mathrm{Na}_{2} \mathrm{SO}_{4}$ & 4.09 \\
$\mathrm{CaCl}_{2}$ & 1.16 \\
$\mathrm{KCl}$ & 0.695 \\
$\mathrm{NaHCO}_{3}$ & 0.201 \\
$\mathrm{KBr}_{3}$ & 1.101 \\
$\mathrm{H}_{3} \mathrm{BO}_{3}$ & 0.027 \\
$\mathrm{SrCl}_{2}$ & 0.025 \\
$\mathrm{NaF}$ & 0.003 \\
\hline
\end{tabular}

\section{Crack Length Estimation and J-Parameter Calculation}

During fatigue pre-cracking and fracture-toughness testing, estimation of instantaneous crack length was performed using the compliance method, by attaching a clip gauge onto the crack mouth of the specimen. This approach is based on constant load-linedisplacement (LLD) monitoring and calculation of the instantaneous crack length using the elastic-compliance measurements according to Equations (1)-(3), where $a_{i}$ is the instantaneous crack length, $C_{i}$ is the instantaneous unloading compliance, $E$ is the elastic Young's modulus and $B_{e}$ is the effective thickness, which is calculated using the specimen's full thickness, $B$, and net thickness value, $B_{n}$.

$$
\frac{a_{i}}{W}=1.000196-4.06319 u+11.242 u^{2}-106.043 u^{3}+464.335 u^{4}-650.677 u^{5}
$$

where

$$
\begin{gathered}
u=\frac{1}{\left[B_{e} E C_{i}\right]^{\frac{1}{2}}}+1 \\
B_{e}=B-\frac{\left(B-B_{n}\right)^{2}}{B}
\end{gathered}
$$

Fracture-toughness tests were conducted at room temperature on a $100 \mathrm{kN}$ servo hydraulic Instron machine (Instron, Norwood, MA, USA), under LLD control mode, by applying sequences of loading and unloading with $60 \mathrm{~s}$ of hold time at each peak load, followed by $20 \%$ unloading with respect to the peak load value. The loading-unloading rate was $1 \mathrm{~mm} / \mathrm{min}$, and the sequences of unloading were carried out at LLD intervals of $0.125 \mathrm{~mm}$. To plot a resistance curve (i.e., $R$-curve) for each test, the elastic-plastic fracture-mechanics parameter, $J$, was determined using Equation (4), as recommended by 
ASTM E1820 [27]. It can be seen from the equation that the total value of $J$ consists of an elastic and a plastic term, which are calculated using Equations (5) and (6), respectively. In these equations, $K$ is the stress-intensity factor, which varies for different specimen geometries [29]; $v$ is the Poisson's ratio; $a_{0}$ is the initial crack length; $A_{p}$ is the plastic area under the load vs. LLD curve; and $\eta$ is a geometry-dependent function, the solution of which, for the C (T) specimen geometry, is demonstrated in Equation (7).

$$
J=J_{e l}+J_{p l}
$$

where

$$
\begin{gathered}
J_{e l}=\frac{K^{2}\left(1-v^{2}\right)}{E} \\
J_{p l}=\frac{A_{p}}{B_{n}\left(W-a_{0}\right)} \eta \\
\eta=2+\frac{0.522\left(W-a_{0}\right)}{W}
\end{gathered}
$$

To establish the fracture-toughness value, the $R$-curve is generated for each test by plotting $J$ values against the crack extension, $\Delta a$. Then, a construction line (which is also known as the blunting line) is plotted, the slope of which is calculated using Equation (8). In this equation, $\sigma_{Y}$ is the yield stress of the material. According to the ASTM E1820 standard, two exclusion lines are constructed parallel to the construction line, offsetting the abscissa by 0.15 and $1.5 \mathrm{~mm}$. The data points along the $R$-curve that fall between two exclusion lines are considered valid data points, and a line of best fit is built to them. The intersection between the line of best fit and a $0.2 \mathrm{~mm}$ offset parallel to the construction line defines the fracture-toughness value, denoted as $J_{I C}$.

$$
J=2 \sigma_{Y} \Delta a
$$

\section{Fracture-Toughness Test Results}

The load vs. LLD data obtained from four fracture-toughness tests performed on ER70S-6- and ER100S-1-corroded C (T) specimens are presented in Figure 3. Comparison of the curves for different materials shows that the deviation from linearity occurs at a much higher load level in ER100S-1- than in ER70S-6-corroded specimens, due to the higher yield stress [30]. Additionally, it can be seen that the trends for two specimens of the same material look similar; however, for ER70S-6 material, the horizontal specimen exhibits a higher trend compared to the vertical specimen, whereas for ER100S-1, it is the vertical specimen that shows the higher load vs. LLD trend compared to the horizontal specimen.

The results obtained in this study were further compared with the test results of similar C (T) specimens extracted from ER70S-6 and ER100S-1 WAAM walls and tested for fracture toughness in ambient conditions without any environmental exposure (denoted as A) by Ermakova et al. [30], presented in Figure 4. It can be seen in this figure that for both materials, the obtained trends for corroded specimens are lower and longer than for the ambient-tested specimens, indicating that the yield stress is reduced in corrosive environments [23]. The direct comparison of the ER70S-6 specimens extracted from the same location of the wall and with the same orientation presents that A-70-1 (T, V) and C$70-1(T, V)$ have higher trends than specimens with horizontal orientation, A-70-3 $(T, H)$ and C-70-2 (T, H). Hence, the testing environment does not affect the orientation sensitivity of the specimens made with ER70S- 6 welding wire. The scatter between ER100S-1 specimens with different orientations and the same locations is much smaller, and the results fall almost on top of each other. It must be noted here that in this study, the tested corroded specimens were only extracted from the top of the wall, and in a future study, more specimens extracted from the bottom of the WAAM wall will be tested for further comparison of the obtained results with the samples tested without any prior exposure to seawater. 


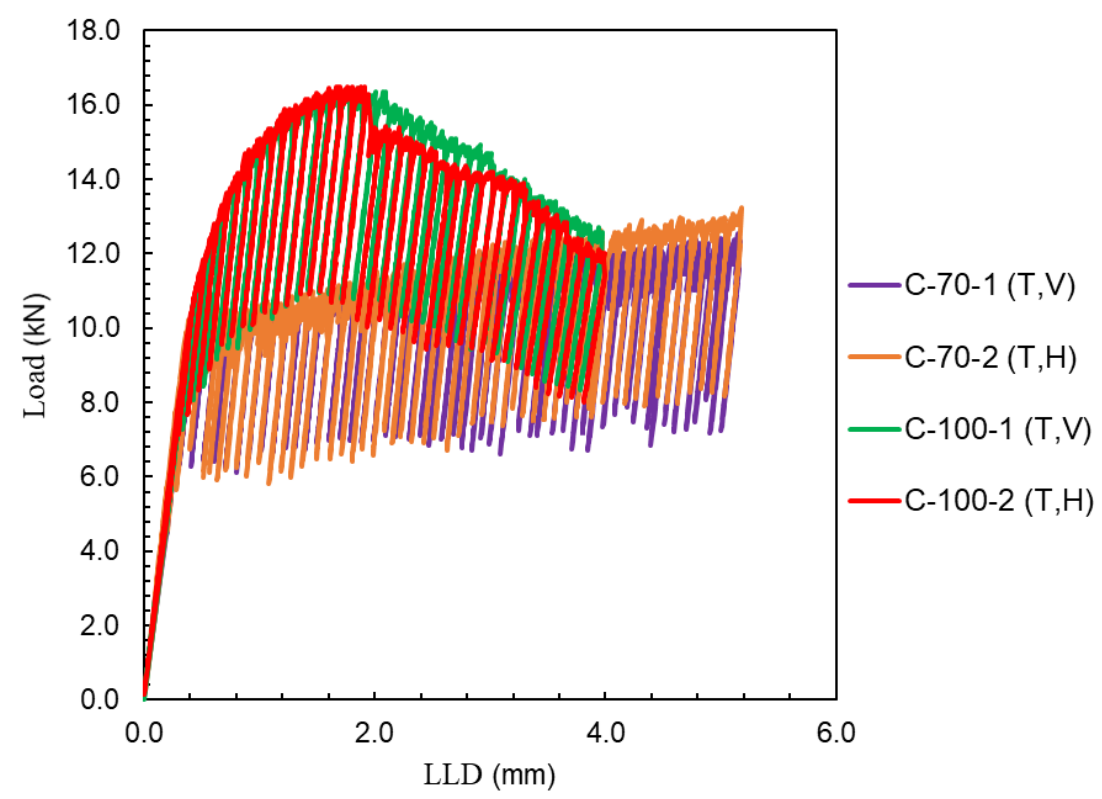

Figure 3. Load vs. LLD for both ER70S-6- and ER100S-1-corroded specimens.

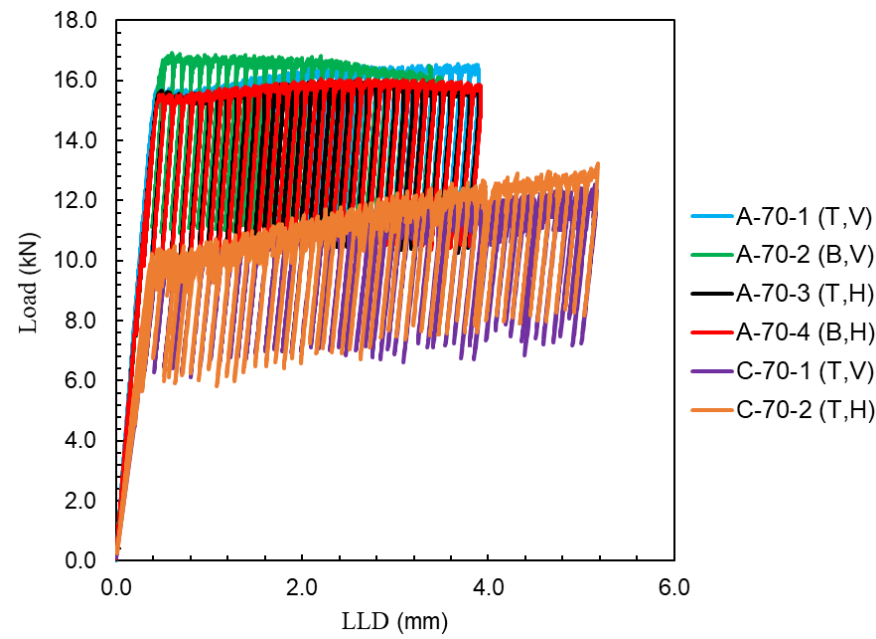

(a)

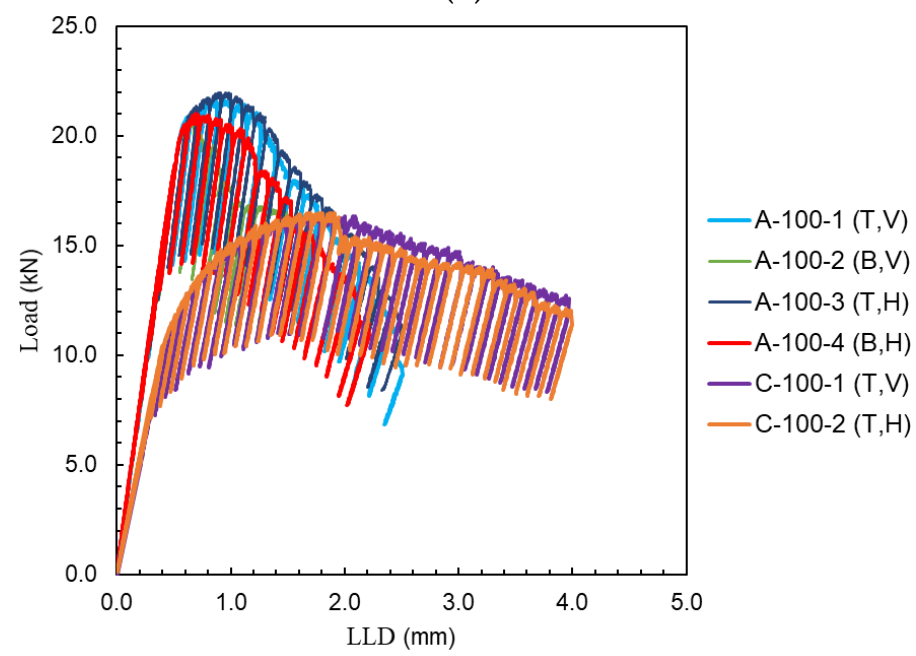

(b)

Figure 4. Comparison of load vs. LLD for (a) ER70S-6 and (b) ER100S-1 specimens tested with and without corrosion exposure. 
Fracture-toughness resistance curves were generated for four tested corroded specimens and are shown in Figure 5. It can be seen in this figure that the $R$ curves for the specimens extracted from the ER70S-6 wall show much higher trends than those extracted from the ER100S-1 wall, indicating that more energy is required to propagate cracks in specimens made of WAAM ER70S-6 material. The scatter for vertical and horizontal specimens for each material is small, and they almost overlap each other. An example of the detailed fracture-toughness analysis by plotting the blunting and exclusion lines, as well as determining the $J_{I C}$ value from the valid data points, is displayed in Figure 6a for the C-100-1 specimen. The $J_{I C}$ values for ER100S-1-corroded specimens are summarised in Table 4. The fracture-toughness analysis of ER70S-6-corroded specimens revealed that no valid data points can be determined from the collected test data, as shown for the C-70-1 specimen in Figure $6 \mathrm{~b}$. Therefore, $J_{I C}$ values for ER70S-6-corroded specimens could not be quantified and compared in this study. However, as concluded above, material properties change due to corrosion damage; therefore, the slope of the blunting lines for both materials would change, as they depend on the material properties (Equation (8)). Therefore, the valid points and $J_{I C}$ values will differ. In future work, the tensile material properties of corroded specimens will be determined in order to alter the blunting and exclusion lines for quantification of $J_{I C}$ values.

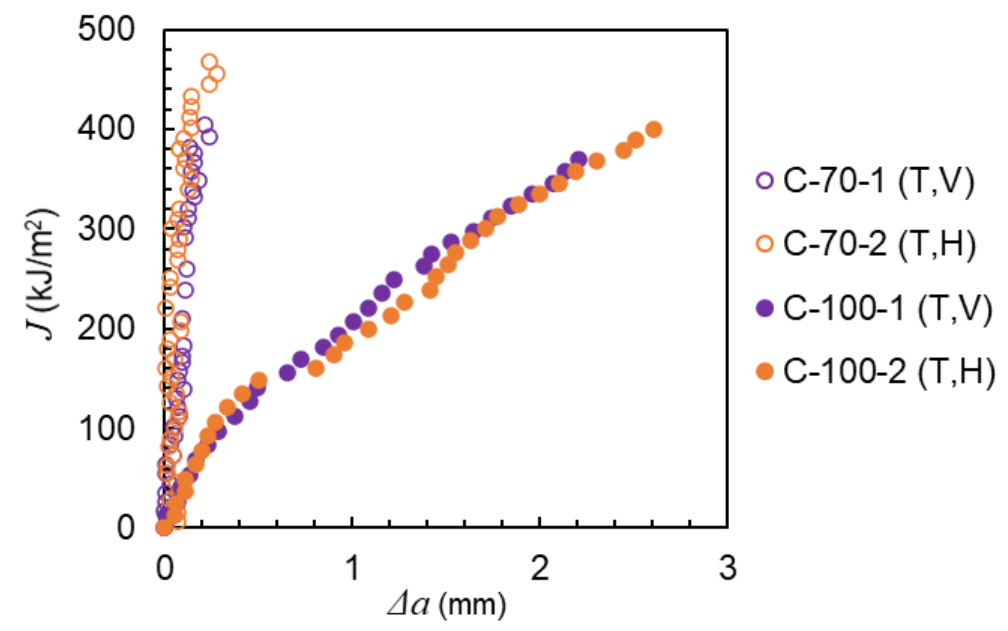

Figure 5. Resistance curves for ER70S-6- and ER100S-1-corroded specimens.

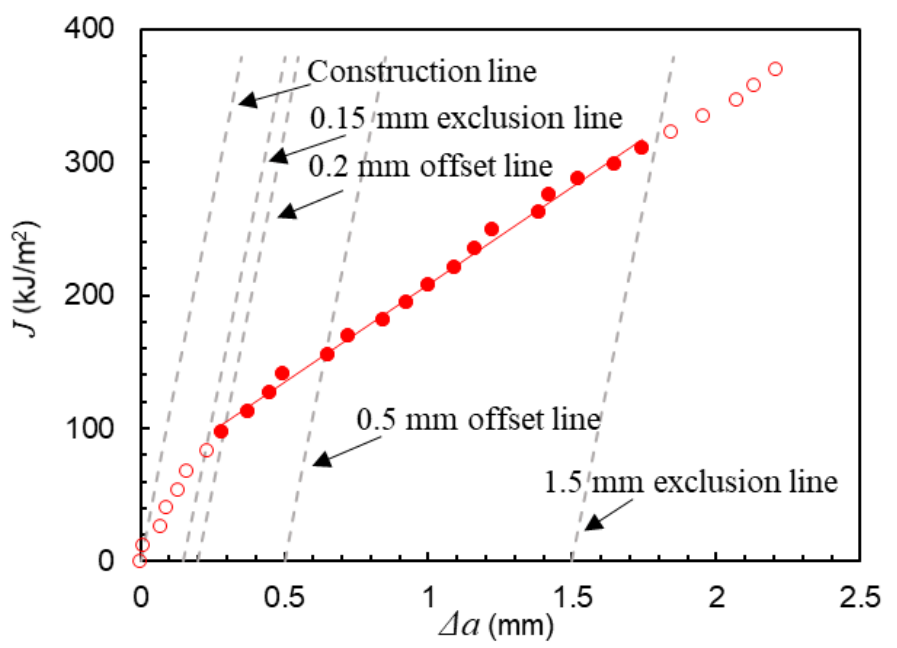

(a)

Figure 6. Cont. 


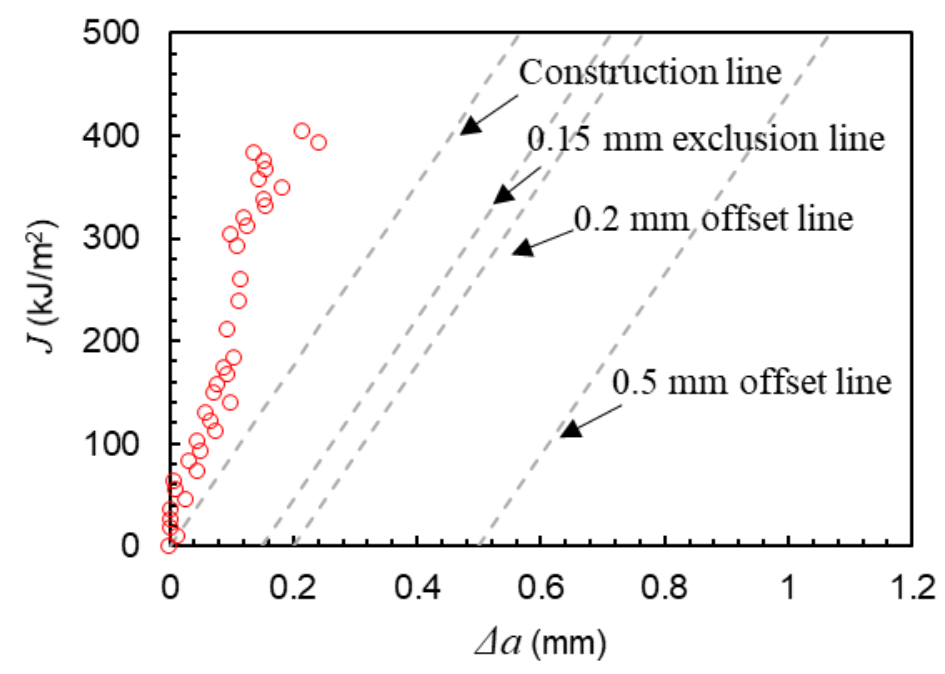

(b)

Figure 6. Analysis of the fracture-toughness data for (a) C-100-1 and (b) C-70-1 specimens.

Table 4. Fracture-toughness values for ER100S-1-corroded specimens.

\begin{tabular}{ccc}
\hline Specimen ID & $\begin{array}{c}\text { C-100-1 } \\
(\mathbf{T}, \mathbf{V})\end{array}$ & $\begin{array}{c}\text { C-100-2 } \\
\mathbf{( T ,}, \mathbf{H})\end{array}$ \\
\hline$J_{I C}\left(\mathrm{~kJ} / \mathrm{m}^{2}\right)$ & 104.2 & 109.0 \\
\hline
\end{tabular}

Comparison of the resistance curves obtained in this study on corrosion-exposed specimens with curves obtained in the study of Ermakova et al. [30] on ER70S-6 and ER100S-1 ambient specimens without any prior corrosion exposure is displayed in Figure 7. As seen in this figure, the slope of the curve is greater for corroded specimens for both of the WAAM-built materials, indicating that a higher level of energy is required to propagate cracks in corroded specimens than in ambient specimens. As previously observed for ambient specimens, the $R$ curves for specimens extracted from the same location fall on top of each other, despite the orientation, and the same trend is seen for corroded specimens extracted from the top of the WAAM walls. Analysis of $J_{I C}$ values for ER100S-1 specimens demonstrates that for corroded specimens, $J_{I C}$ increased, on average, by $61 \%$, compared with values for ambient specimens [30].

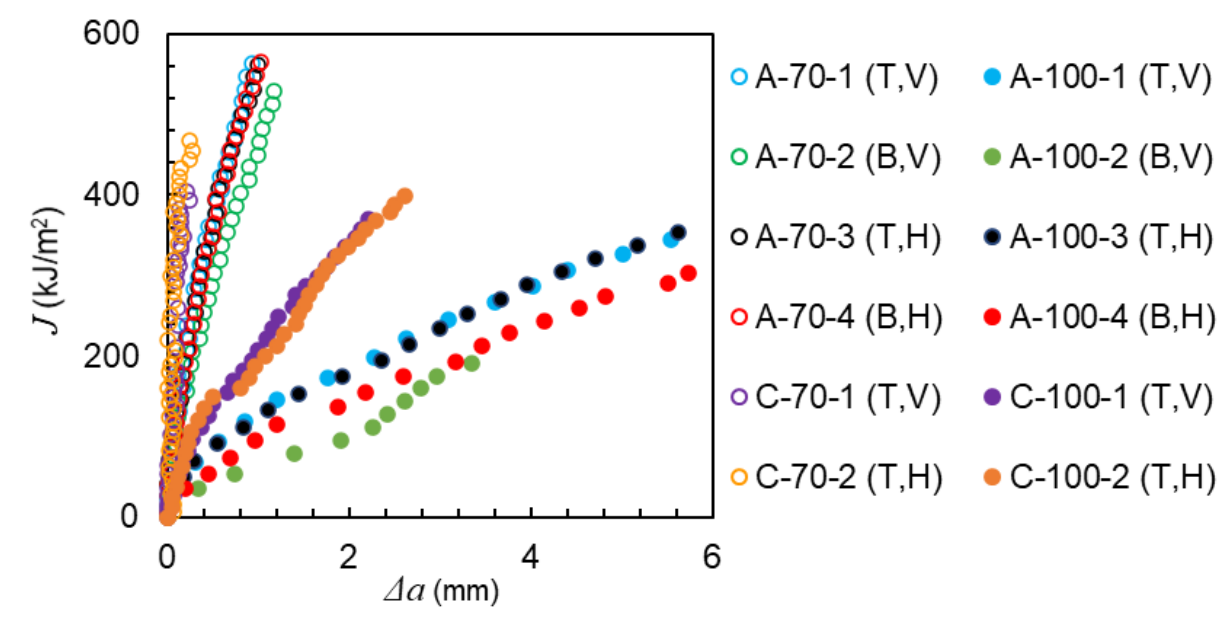

Figure 7. Comparison of resistance curves for ER70S-6 and ER100S-1 specimens with and without exposure to seawater. 
The higher level of fracture energy in corroded WAAM-built specimens, compared to the samples without any prior exposure to seawater, can be associated with the fact that the corrosion process significantly altered not only the mechanical properties but also the sharpness of the crack tip in seawater-exposed specimens. In other words, the results obtained from this study suggest that in both ER70S-6 and ER100S-1 WAAMbuilt specimens, exposure to seawater resulted in a significantly blunter crack tip, which subsequently elevated the $R$ curves in the fracture analysis. This indicates that while corrosion exposure is known to be a damaging mechanism, in the case of WAAM-built components, it can enhance fracture properties by blunting the sharp fatigue-crack tips created due to the cyclic loading effects exerted on offshore structures. Therefore, the provisional results of this study show that the WAAM technique has great potential for application in the offshore wind industry; however, other design considerations, such as fatigue, must be investigated in more detail before employing this efficient AM technique in fabrication or repair of offshore wind-turbine structures.

\section{Conclusions}

Fracture-toughness tests were conducted on WAAM-built specimens made with ER70S-6 and ER100S-1 welding wires. The specimens were immersed in seawater for 11 days prior to fracture testing in order to introduce corrosion effects in the test specimens. The results of this study were compared with those available for similar samples without exposure to seawater. The following conclusions and observations can be drawn from this study:

- The corrosive environment reduces the yield stress of the material; hence, load vs. LLD curves show lower trends for corroded specimens for both ER70S-6 and ER100S-1 materials.

- The $R$ curves for corroded specimens are higher than those obtained from specimens without prior corrosion exposure; thus, a greater level of energy is required to propagate cracks in corroded specimens. The $J_{I C}$ value for ER100S-1-corroded specimens is increased, on average, by $61 \%$ compared with $J_{I C}$ values on the same material without corrosion exposure.

- The corrosion process alters the mechanical properties in WAAM-built specimens and possibly makes the fatigue cracks blunter, which subsequently leads to improved fracture properties.

- The WAAM technique has been demonstrated to have great potential for employment in offshore applications, particularly manufacturing and repair of offshore windturbine structures.

- Tensile properties of corroded specimens need to be investigated in future work in order to improve the construction process of blunting and exclusion lines.

Author Contributions: Conceptualization, A.M.; methodology, A.E.; formal analysis, A.E.; writingoriginal draft preparation, A.E.; writing — review and editing, A.M. All authors have read and agreed to the published version of the manuscript.

Funding: This work was supported by grant EP/L016303/1 for Cranfield, Oxford and Strathclyde Universities' Centre for Doctoral Training in Renewable Energy Marine Structures-REMS CDT (http:/ / www.rems-cdt.ac.uk/, accessed on 10 December 2021) from the UK Engineering and Physical Sciences Research Council (EPSRC).

Data Availability Statement: Not applicable.

Conflicts of Interest: The authors declare no conflict of interest. 


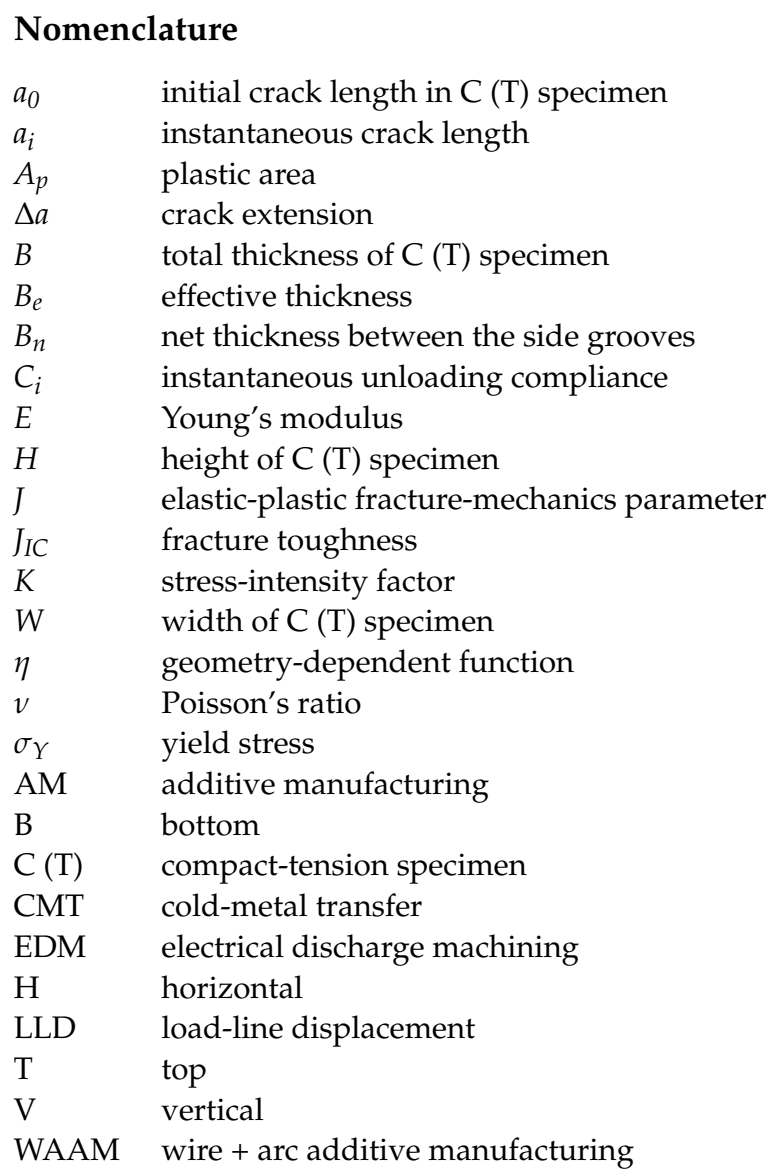

\section{References}

1. Berto, F.; Lazzarin, P. Recent developments in brittle and quasi-brittle failure assessment of engineering materials by means of local approaches. Mater. Sci. Eng. R Rep. 2014, 75, 1-48. [CrossRef]

2. Pidaparti, R.M.; Rao, A.S. Analysis of pits induced stresses due to metal corrosion. Corros. Sci. 2008, 50, 1932-1938. [CrossRef]

3. Kainuma, S.; Jeong, Y.-S.; Ahn, J.-H. Investigation on the stress concentration effect at the corroded surface achieved by atmospheric exposure test. Mater. Sci. Eng. A 2014, 602, 89-97. [CrossRef]

4. Williams, S.; Martina, W.F.; Addison, A.C.; Ding, J.; Pardal, G.; Colegrove, P. Wire + Arc Additive Manufacturing. Mater. Sci. Technol. 2015, 32, 641-647. [CrossRef]

5. Derekar, K.S. A review of wire arc additive manufacturing and advances in wire arc additive manufacturing of aluminium. Mater. Sci. Technol. 2018, 34, 895-916. [CrossRef]

6. Haden, C.; Zeng, G.; Carter, F.; Ruhl, C.; Krick, B.; Harlow, D. Wire and arc additive manufactured steel: Tensile and wear properties. Addit. Manuf. 2017, 16, 115-123. [CrossRef]

7. Marinelli, G.; Martina, F.; Lewtas, H.; Hancock, D.; Ganguly, S.; Williams, S. Functionally graded structures of refractory metals by wire arc additive manufacturing. Sci. Technol. Weld. Join. 2019, 24, 495-503. [CrossRef]

8. Liljedahl, C.; Brouard, J.; Zanellato, O.; Lin, J.; Tan, M.; Ganguly, S.; Irving, P.; Fitzpatrick, M.; Zhang, X.; Edwards, L. Weld residual stress effects on fatigue crack growth behaviour of aluminium alloy 2024-T351. Int. J. Fatigue 2009, 31, 1081-1088. [CrossRef]

9. Xu, X.; Ganguly, S.; Ding, J.; Guo, S.; Williams, S.; Martina, F. Microstructural evolution and mechanical properties of maraging steel produced by wire + arc additive manufacture process. Mater. Charact. 2018, 143, 152-162. [CrossRef]

10. Seow, C.E.; Zhang, J.; Coules, H.E.; Wu, G.; Jones, C.; Ding, J.; Williams, S. Effect of crack-like defects on the fracture be-haviour of Wire + Arc Additively Manufactured nickel-base Alloy 718. Addit. Manuf. 2020, 36, 101578.

11. Xu, S.-H.; Wang, Y.-D. Estimating the effects of corrosion pits on the fatigue life of steel plate based on the 3D profile. Int. J. Fatigue 2015, 72, 27-41. [CrossRef]

12. Xu, S.; Wang, H.; Li, A.; Wang, Y.; Su, L. Effects of corrosion on surface characterization and mechanical properties of butt-welded joints. J. Constr. Steel Res. 2016, 126, 50-62. [CrossRef]

13. Wang, Y.; Xu, S.; Wang, H.; Li, A. Predicting the residual strength and deformability of corroded steel plate based on the corrosion morphology. Constr. Build. Mater. 2017, 152, 777-793. [CrossRef]

14. Qin, G.-C.; Xu, S.-H.; Yao, D.-Q.; Zhang, Z.-X. Study on the degradation of mechanical properties of corroded steel plates based on surface topography. J. Constr. Steel Res. 2016, 125, 205-217. [CrossRef] 
15. Kim, I.-T.; Dao, D.K.; Jeong, Y.-S.; Huh, J.; Ahn, J.-H. Effect of corrosion on the tension behavior of painted structural steel members. J. Constr. Steel Res. 2017, 133, 256-268. [CrossRef]

16. Garbatov, Y.; Soares, C.G.; Parunov, J.; Kodvanj, J. Tensile strength assessment of corroded small scale specimens. Corros. Sci. 2014, 85, 296-303. [CrossRef]

17. Appuhamy, J.M.R.S.; Kaita, T.; Ohga, M.; Fujii, K. Prediction of residual strength of corroded tensile steel plates. Int. J. Steel Struct. 2011, 11, 65-79. [CrossRef]

18. Ahmmad, M.; Sumi, Y. Strength and deformability of corroded steel plates under quasi-static tensile load. J. Mar. Sci. Technol. 2009, 15, 1-15. [CrossRef]

19. Wang, H.; Xu, S.; Li, A.; Kang, K. Experimental and numerical investigation on seismic performance of corroded welded steel connections. Eng. Struct. 2018, 174, 10-25. [CrossRef]

20. Nakai, T.; Matsushita, H.; Yamamoto, N. Effect of pitting corrosion on strength of web plates subjected to patch loading. Thin-Walled Struct. 2006, 44, 10-19. [CrossRef]

21. Nakai, T.; Matsushita, H.; Yamamoto, N. Effect of Pitting Corrosion on Ultimate Strength of Web Plates Subjected to Shear Loading. Key Eng. Mater. 2007, 340, 489-494. [CrossRef]

22. Zhang, H.; Xu, S.; Nie, B.; Wen, Y. Effect of corrosion on the fracture properties of steel plates. Constr. Build. Mater. 2019, 225, 1202-1213. [CrossRef]

23. Hou, Y.; Lei, D.; Li, S.; Yang, W.; Li, C.-Q. Experimental Investigation on Corrosion Effect on Mechanical Properties of Buried Metal Pipes. Int. J. Corros. 2016, 2016, 5808372. [CrossRef]

24. Lincoln Electric Company. Lincoln ${ }^{\circledR}$ ER70S-6 Welding Positions Typical Applications. Available online: www.lincolnelectric.com (accessed on 28 October 2021).

25. ER100S-G Data Sheet-Bohler Welding. Available online: www.voestalpine.com/welding (accessed on 5 December 2021).

26. Ermakova, A.; Mehmanparast, A.; Ganguly, S. A review of present status and challenges of using additive manufacturing technology for offshore wind applications. Procedia Struct. Integr. 2019, 17, 29-36. [CrossRef]

27. American Society for Testing and Materials. ASTME-1820-11: Standard Test Method for Measurement of Fracture Toughness; Annual Book of ASTM Standards 1-55; American Society for Testing and Materials: West Conshohocken, PA, USA, 2011. [CrossRef]

28. American Society for Testing and Materials. D1141-98: Standard Practice for the Preparation of Substitute Ocean Water; ASTM International: West Conshohocken, PA, USA, 2013; Volume 98, pp. 1-3.

29. Anderson, T.L. Fracture Mechanics: Fundamentals and Application; Taylor \& Francis Group: Abingdon-on-Thames, UK, 2005.

30. Ermakova, A.; Mehmanparast, A.; Ganguly, S.; Razavi, J.; Berto, F. Investigation of mechanical and fracture properties of wire and arc additively manufactured low carbon steel components. Theor. Appl. Fract. Mech. 2020, 109, 102685. [CrossRef] 